\title{
La tisis del alma: la enfermedad y el viaje en Gorriti
}

\section{Consumption of the Soul: illness and travel in Gorriti}

\author{
Rocío del Aguila ${ }^{1}$
}

\section{Resumen}

En este ensayo, se analiza a Laura, el personaje principal de Peregrinaciones de una alma triste para discutir el proceso por el que la agencia del sujeto femenino subvierte el orden simbólico. Se utiliza el concepto del pharmakon, como lo utiliza Jacques Derrida, en dos niveles para mostrar la relación compleja que existe entre pacientes femeninos y la enfermedad, y también para elucidar la situación de la mujer en cuanto al viaje y al exilio.

Palabras clave: Gorriti, enfermedad, viaje, escritura, pharmakon

1 Wichita State University. Profesora Asistente.

Contacto: rociodelaguila@gmail.com 


\section{Abstract}

In this essay I will analyze Laura, the main character from $P e-$ regrinaciones de una alma triste in order to discuss the process by which the agency of the feminine subject subverts the symbolic order. I will apply the concept of Pharmakon, as used by Jacques Derrida, on two different levels to show the complex relation between women patient and illness; and also to elucidate the situation of women while traveling and in exile.

Keywords: Gorriti, illness, travels, writing, pharmakon

$$
* * *
$$

\section{La tisis del alma: la enfermedad y el viaje en Gorriti}

Mañana me despertaré en la estancia, pensaba, y era como si a un tiempo fuera dos hombres: el que avanzaba por el día otoñal y por la geografía de la patria, y el otro, encarcelado en un sanatorio y sujeto a metódicas servidumbres. (Jorge Luis Borges. "El Sur”.)

Este ensayo intenta entender las estrategias de resistencia y de subversión de Gorriti, aun cuando muchos la consideran una escritora conservadora. En particular, interesa su visión del género frente a lo patriarcal para entender en qué medida su escritura critica la lógica que estructura este sistema y no se limita solamente a lo superficial. Por lo tanto, se propone una lectura de temas que son constantes en la producción de la escritora y que se entrelazan perfectamente en Peregrinaciones. Este estudio es temáticamente bipartito: la primera parte está relacionada con la medicina, y la segunda con el viaje y el exilio. ${ }^{2}$ El texto de Gorriti se publicó en 1876 en Buenos

2 El texto original incluía una tercera parte acerca de la escritura, que se ha eliminado por motivos de espacio y en el que se analizaba también el 
Aires, pero se compone de relatos que aparecieron sueltos en revistas o como episodios de una obra mayor, a modo de folletines entre 1850 y 1870, y fueron escritos durante esa época cuando ella residía exiliada en Lima. El lugar de escritura, sumado al extenso rango temporal de producción, permite relacionar el texto con la realidad peruana tanto como con la argentina, y se puede adjudicar la producción de las historias intercaladas a varios años previos a su publicación. Esta lectura añade al cuerpo crítico de la obra gorritiana para entender lo significativo de su escritura en diversos países.

El tema médico muestra varios de los cambios abruptos del siglo, como la profesionalización de los galenos, el énfasis en el positivismo y la apertura del sistema tradicional de atención médica. Por este motivo, es también la materia que se trata más extensamente en el ensayo. ${ }^{3}$ La medicina respalda la posición de sus practicantes en un marco paternalista que les otorga injerencia en las decisiones familiares $y$, en este caso en particular, en las que conciernen a la mujer. Esta situación no es una invención literaria, sino un hecho que se comprueba en intervenciones e inventarios médicos de la época. Por otra parte, el análisis se centrará en las heroínas tísicas que son altamente poetizadas en su versión literaria, pero que también lidian con el problema existente de la enfermedad. El diagnóstico médico puede limitar la actividad física de la mujer, pero aún más, puede

discurso de la enfermedad. En otra publicación, se hará énfasis en este tema fundamental en Peregrinaciones siguiendo criterios similares a los del presente artículo.

3 Este ensayo pertenece a un proyecto más extenso en el que se compara a Gorriti con otros escritores de su círculo intelectual en el Perú (Matto de Turner, Cabello de Carbonera) en varios temas. 
interferir en su desarrollo cuando se refiere a patologías psicológicas o a efectos psicosomáticos de las enfermedades. También se presenta el caso de la muerte por amor de corte romántico y cómo esta se entrelaza con las dolencias físicas del amante. Salvando las distancias entre el viejo y el nuevo continente, los doctores se oponían a las oportunidades de desarrollo dadas por el trabajo y la educación a las mujeres y las explicaban médicamente: "[...] doctors warned them that pursuit of such opportunities would lead to sickness, sterility, and race suicide. They explicitly linked the epidemic of nervous disorders -anorexia nervosa, hysteria, and neurasthenia- which market the fin de siècle to women's ambition" (Showalter 1985: 121). ${ }^{4}$ Si bien Showalter resume cómo el desarrollo científico permite profundizar la diferencia de género en Europa, es posible adaptar esta concepción a la realidad latinoamericana, debido a que la vida de las mujeres fue afectada con la preeminencia de ciertas ideas, foráneas o nacionales, acerca del tratamiento médico.

El otro motivo extenso es el viaje, que es tema frecuente en la narrativa de Gorriti y fundamental en la economía narrativa de Peregrinaciones. El viaje se presenta como exilio, escape, sanación, necesidad vital, además de que Laura deviene en Laura a través de él. Por ser la vida de Gorriti tan particular

4 “[...] los médicos les advirtieron que la búsqueda de tales oportunidades conduciría a enfermedades, esterilidad y suicidio racial. Ellos explícitamente vincularon la epidemia de trastornos nerviosos - anorexia nerviosa, histeria y neurastenia - que anunciaba el final de siglo a la ambición de las mujeres." (Showalter 1985: 121). Salvo que se indique lo contrario, las traducciones de las citas del inglés al español son de la autora del ensayo. 
en cuanto a nacionalidad, exilio y movilidad, se asume que su lugar de enunciación es diferente al de otros escritores y que ella propone su discurso desde la liminalidad y a través de ella. La singularidad de la protagonista se queda a la zaga al compararse con la vida extraordinaria de una mujer que vivió a caballo entre varios países y que sobrepasó las aventuras de sus personajes.

Particularmente en esta novela, el viaje es el motivo que organiza el relato cumpliendo con la función textual de activar los mecanismos de la narración y el traslado físico se convierte en una constante. También se recrean espacios de escapismo en el viaje de retorno a la infancia y lugares heterotópicos en este éxodo supuestamente obligado de la protagonista. Tanto Gorriti como otras mujeres intelectuales de su época vivieron en carne propia la arbitrariedad y el desplazamiento forzado. Tal vez por sus experiencias personales, la autora logra forjar personajes que deambulan en espacios vedados y se enfrentan a sistemas normalizados utilizando argucias femeninas poco tradicionales. Temas como el escapismo a través de la lectura, la narración de viaje o la utopía del retorno se analizan para determinar el efecto traumático del entorno en sus vidas y su consiguiente relación con el acto de escritura.

El concepto del pharmakon utilizado por Jacques Derrida en Plato's Pharmacy (1972) se empleará como la base teórica para desarrollar los dos temas, porque se adapta a las necesidades del uso médico que corresponde a la primera parte y, luego, se enlaza con la siguiente. En la primera sección del ensayo derrideano, se expone la ambivalencia del término pharmakon en cuanto cura y veneno; luego, se parte de esta ambigüedad para mencionar lo que no logra ser comprendido en las cate- 
gorías platónicas bosquejadas por el propio Platón y se elabora en las posibilidades de la significación a partir de la diferencia de los signos. Derrida también incluye diatribas contra la preeminencia del habla sobre la escritura en el Fedro, ${ }^{5}$ que llama "logocentrismo", y la distinción entre los espacios interno y externo. Si bien el concepto del pharmakon tiene que ver con un uso constante del autor para referirse al análisis postestructuralista en sus intentos por explicar la ambigüedad en una lectura deconstructivista de Platón, es difícil salir del concepto de opuestos binarios y pasar a un sistema aporético de opuestos que se anulan, pero que, a la vez, se nutren y de los cuales quedan trazos textuales. Aunque el ensayo de Derrida presenta un extenso contenido, estos son algunos de los asuntos que atañen a este capítulo y que se sirven para desarrollar la secuencia temática. Adicionalmente, se utilizará el concepto de heterotopia, como lo define Foucault en su ensayo no publicado Of other Spaces. Heterotopias (1967), en relación con el motivo del viaje. De modo similar a la mención a Showalter, la investigación se nutre de crítica feminista para explicar la situación de la mujer en el esquema patriarcal y la interseccionalidad de la época.

\section{La tisis}

Laura se bifurca imaginariamente en la joven que retorna a su patria y aquella que permanece inmovilizada en su cama, e incluso luego de su partida parece escindida, porque debe elegir constantemente entre dos polos: aquel de su realidad

5 El Fedro es el diálogo platónico que sirvió de base para el análisis de Derrida en Plato's Pharmacy — traducido como La farmacia de Platón-y se encarga de varios temas, tales como la filosofía, el sofismo, la escritura, la memoria, etcétera. 
y el otro de su felicidad imaginada. Al inicio del libro, la protagonista no se encuentra en un sanatorio, sino en su casa, bajo el cuidado de su madre y sus hermanos, que la atienden fervorosos porque ella ha sido desahuciada. Frente a la alternativa de la muerte, la joven enferma decide utilizar un último recurso y se arriesga a emprender el viaje solitario hacia la tierra natal:

¿Cómo insinuar, siquiera, mi resolución, sin que la juzguen una insigne locura?... Y, sin embargo, me muero, iy yo quiero vivir! jvivir para mi madre, para mis hermanos, para este mundo tan bello, tan rico de promesas cuando tenemos veinte años! Mis ojos están apagados, y quiero que, como dice el doctor, resplandezcan; que mis labios recobren su color y mi carne su frescura. Quiero volver a la salud a la belleza; muy joven soy todavía para morir. ¡Huyamos!. (Gorriti 2006: 5).

No existe un sujeto colectivo, no hay un nosotros. Es un engaño gramatical, porque el viaje no lo va a realizar la joven con sus diligentes hermanos que la cargan en brazos para que no camine ni con su madre que la llora cada noche ni con la junta de médicos que ha declarado que ella es incapaz de soportar el viaje a la sierra para cambiar de aires. El viaje lo va a efectuar la joven sola y en total secrecía, porque sabe que, de otro modo, no se lo van a permitir. Viajar se traduce para ella en vivir, mientras que, para los médicos, significa morir, es decir, lo diametralmente opuesto.

La paciente se ha decidido por este método sanador, porque su médico ha mencionado el caso de un tuberculoso en grado avanzado que se salvó al emprender un viaje interminable de puerto en puerto. Es la transformación del tísico por motivos románticos: "In the nineteenth century, the notion that the disease fits the patients' character, as the punishment fits the 
sinner, was replaced by the notion that it expresses character. Disease can be challenged by the will" (Sontag 1989: 43), ${ }^{6}$ una visión romantizada del tísico que expresa determinación y personalidad a decir de Sontag. Dos hechos, que se presentan casi simultáneamente, desencadenan los deseos en la paciente. El primero es el relato de esa historia que ha desatado visiones esperanzadas de bienestar en ella y el segundo es el uso del arsénico que el médico ha decidido utilizar: "[...] dé el alma a la fe y abandone su cuerpo a la misteriosa acción del terrible específico, veneno activísimo, y por eso mismo, algunas veces, milagroso remedio" (Gorriti 2006: 4). Extrañamente, el discurso del médico es tan ambivalente acerca de su prescripción como cuando relata la historia de su otro paciente tísico. Coincidentemente, es él mismo quien introduce esa opción sanadora en el relato mientras conversa de medicina homeopática. También el que sea él mismo quien lo menciona le otorga valor médico y, además, queda como precedente de lo que hacen pacientes suyos que se enfrentan a su tratamiento; incluso Laura propone que es a partir del relato del médico que ella logra sanarse. Reconoce que el viaje salvó al hombre, pero no entiende por qué y lo justifica como un caso excepcional, mientras que, en el caso de la poción, no presenta mayor seguridad en cuanto a sus resultados: "Desde hoy comienza usted a tomar para curarse aquello que a otros da la muerte: el arsénico. Arsénico por la

32 mañana, arsénico en la tarde, arsénico en la noche.... ¡Horrible! ¿No es cierto?” (Gorriti 2006: 4). Aunque el uso del arsénico fue cayendo en desuso, la realidad histórica es que

6 "En el siglo XIX la idea de que la enfermedad se ajustaba a la personalidad del paciente, tal como el castigo al pecador, es reemplazada por la noción que aquella expresaba su carácter. La enfermedad podía ser desafiada por la voluntad" (Sontag 1989: 43). 
este elemento químico ha sido utilizado al mismo tiempo como veneno y como remedio, puesto que puede cumplir con ambas funciones. Es un perfecto ejemplo de un fármaco como lo menciona Derrida: "This pharmakon, this 'medicine', this philter, which acts as both remedy and poison, already introduces itself into the body of the discourse with all its ambivalence. This charm, this spellbinding virtue, this power or fascination, can be -alternately or simultaneouslybeneficent or maleficent" (1981: 70). ${ }^{7}$ Esta inestabilidad discursiva producida por los elementos que no engañan al lector y permite que la elección de la enferma no parezca absurda porque el químico está medrando su salud y el lector, ansioso de emprender el viaje, la sigue.

En el caso de la tuberculosis, se reconocía que los pacientes podían mejorar mucho en un ambiente seco e incluso curarse por este cambio ambiental. Se entiende la tisis como una enfermedad de las ciudades húmedas que calaban los huesos de sus residentes (Sontag 1981: 15). Por eso, se recomendaba partir de la húmeda Lima y viajar hacia la sierra. El viaje de recuperación o el turismo médico sí eran una posibilidad, pero implicaban una serie de convenciones que no se consideran en este relato. Es sabido que, en esta época, las náuseas en las embarcaciones afectaban a los tripulantes; el recorrido a caballo era físicamente extenuante y, en general, el viaje en sí resultaba arriesgado por los incipientes medios de transporte y lo desolado de algunos parajes. Estos peligros, sumados a que

7 'Este pharmakon, esta 'medicina', esta poción, que actúa como remedio y como veneno, se introduce asimismo en el cuerpo del discurso con toda su ambivalencia. Este encanto, esta fascinante cualidad, este poder de fascinación, puede ser —alternativa o simultáneamente- benéfico o maléfico" (1981: 70). 
la protagonista es una joven convaleciente que viaja aislada, son suficiente motivo para detener el proyecto; sin embargo, se asume el viaje como la única esperanza frente a la ineficacia del sistema médico. Recién a mediados del siglo XIX se inventó la antisepsia en los hospitales y, aunque los sistemas modernos - fruto del positivismo científico- estaban en boga, su implementación resultaba complicada, así que, incluso a comienzos del siglo XX, no se utilizaban dispositivos de desinfección e higiene básicos. En el caso de Buenos Aires, el higienismo se comenzó a implementar alrededor de 1850; en el caso de Lima, donde se escribió la mayoría de estos relatos, los grandes cambios hospitalarios ocurrieron recién a finales de siglo, y empezó a introducirse este discurso en el texto. ${ }^{8}$

El sistema positivista y la concepción moderna de la medicina incitan al uso de insumos farmacéuticos, porque el producto del método científico es infalible. Este razonamiento queda en tela de juicio cuando la protagonista rompe con el sistema paternalista médico al que está sometida para emprender un viaje curativo, y su pronta mejoría prueba la existencia de un cierto relativismo entre la cura y la enfermedad. La existencia de esta duda es suficiente para cuestionar

8 Aunque muchas de las escritoras peruanas como Matto de Turner, González de Fanning y Cabello de Carbonera eran discípulas y asiduas a la tertulia de la Gorriti, es recién a partir de 1880 que, en la producción literaria femenina de Lima, se pueden encontrar textos con un discurso higienista (Mannarelli 1999: 19-20). Es alrededor de esa fecha que, en Argentina, también las mujeres escritoras se preocupan por manipular el discurso científico, incluso para rebatir los preceptos de la filosofía social con fundamento cientifista, como aquel que postula que la mujer era inferior al hombre, y, como indica Francine Masiello, construir una evaluación científica propia acerca de la vida doméstica, los eventos públicos y aun el cuerpo femenino (1992: 92). 
el sistema positivista que la sustenta y que no aceptaría opciones intermedias, $\mathrm{y}$, menos aún, resultados opuestos a los planificados. Para ponerlo en el contexto de la historia, el viaje puede curar o matar al paciente, como un pharmakon, o, como se verá, ambos simultáneamente. Sin embargo, no parece un cuestionamiento al positivismo, sino que la situación exhibe la falta de conocimiento de lo que en ese momento son las ciencias médicas. Derrida trata de discernir entre el conocimiento profundo de las ciencias médicas frente a la lectura superficial de un libro que instruye acerca de temas médicos y drogas farmacéuticas a una persona sin la correcta preparación (1981: 72). Cierto es que la instrucción médica era limitada y que, en el siglo XIX, se encuentran varias seudociencias en boga, como la frenología o la grafología. Con esta idea en mente, se puede vislumbrar indicios de una inadecuada praxis, poca preparación y conocimiento en la descripción del médico y su relación con la paciente. Laura afirma: "El doctor era un nulo" (Gorriti 2006: 3), porque percibe sus incoherencias $y$, al parecer, el único modo de anular su poder es escapar de su rango de influencia.

Tal vez en esto reside la lógica de ese viaje. Las clases adineradas no van a un hospital, sino que se les atiende en casa y el papel del médico se extiende a varios dominios, sin que el conocimiento científico tenga un valor particular. Solo a comienzos del siglo XX, se recomiendan cambios a nivel médico que provocan un desplazamiento del espacio privado al espacio público. Podemos argüir que la joven no escapa de la medicina, sino del médico, quien representa una autoridad en una casa donde no hay padre. María Emma Mannarelli resume con claridad las funciones del médico en la casa y equipara su figura a la de un sacerdote por su capacidad de ingresar al espacio privado: 
La palabra de los médicos obtiene una incidencia particular en la intimidad de las mujeres, es decir, en el mundo privado propiamente dicho. [...] Primero, a través de los temas propiamente dichos que forman parte de la agenda médica: la salud de las mujeres, la higiene, el cuidado del cuerpo. Por otro lado, a través de la presencia física del 'médico de cabecera'. (1999: 19).

En este personaje, se concentra el capital simbólico ${ }^{9}$ y esta acumulación de prestigio le permite expresarse sin restricciones en un ambiente hogareño del que se adueña cuando está presente. No se sabe cuánto de medicina conoce el médico, pero, por su descripción, el lector se entera de que su autoridad está basada en la relación que tiene con la familia y que su fama profesional lo precede. El discurso del médico no da un valor positivo y cuantificable al uso del arsénico. Como se indicó, él ingresa al texto "las excelencias de la homeopatía” con la historia del viajero y él quien mezcla pócimas de resultado dudoso.

Es este el tipo de médico y de medicina que se ejerce en esa época y, en ese sentido, se puede afirmar que Gorriti se enfrenta más al discurso patriarcal que al discurso científico al liberar a su personaje. Sin embargo, no es posible enfrentar uno sin enfrentar el otro. El esquema occidental asigna el poder a la posición del padre donde tanto la ley, el conoci-

36 miento y la ciencia se entreveran. Los médicos participaron en la vida política de los países, no solo con cargos técnicos, sino también como representantes en el parlamento y como autores de la historia nacional (Mannarelli 1999: 48). Escapar

9 Esto implica que este personaje ya tiene acumulados capital social y, posiblemente, capital económico. 
de la casa paterna, del médico como científico y del médico como consejero es subvertir el sistema patriarcal, porque su discurso se irá oficializando para regir en el cuerpo femenino. Lo médico es excluyentemente masculino y, en un período posterior, se convertirá en un discurso normativo en el ambiente público, con lo que logrará reglamentar la vida privada de la mujer (Silva Beauregard 2000).

A diferencia de lo que podría suceder en la realidad, Laura, en el libro, plantea una salida a su situación. Dentro del sistema paternalista médico, se rompe la relación tradicional médico-paciente, pero esto no es producto de la crisis del positivismo, sino de la caracterización del médico; una realidad similar se vivía en Europa, el referente de muchos comportamientos americanos. Aunque la cita se refiere a las enfermedades psicológicas o nerviosas, aislar y curar el espíritu de la paciente era práctica común: "And the medical ideal of a full and radical cure took the form of moral checkmate - the complete submission of the patient to the physician's authority, with a full confession of moral wretchedness and the various tricks and artifices involved in the presentation of the "symptoms" (Showalter 1985: 137). ${ }^{10}$ Felizmente, este galeno no utiliza las curas radicales para obtener la sumisión del paciente que confiesa su propia perversidad. Solo en un momento en el que Laura comenta su visión sanadora de viaje, él menciona que "Esos anhelos fantásticos son endiablados síntomas de enferme-

10 "Y el ideal médico de una cura completa y radical tomaba la forma de un jaque mate moral —la sumisión completa del paciente a la autoridad médica, con una confesión completa de la miseria moral y de los varios trucos y artificios utilizados en la presentación de esos "síntomas"” (Showalter 1985: 137). 
dad" (Gorriti 2006: 8) y se podría entender a la enfermedad como una visión endemoniada o simplemente como un comentario exagerado sin mayor ánimo moralizante católico. La generalización de este abuso médico no es lo único presente en el texto, ya que el hincapié se hace en el doctor; que tenga o no el conocimiento necesario extiende simbólicamente su poder al ámbito moral de esa familia en la que la hija separada del marido debe quedarse en la casa paterna. Aunque esto no se menciona en esta parte del relato, es el trasfondo de la historia de Laura.

Asimismo, el juramento hipocrático, que tiene su base en la cultura griega y que es el compromiso ético de los estudiantes al graduarse de la carrera, no es respetado por este médico. En la ya referida estación del tren, el galeno comenta las intimidades de sus pacientes, yendo en contra del deber del secreto médico: "Guardaré silencio sobre todo aquello que, en mi profesión, o fuera de ella, oiga o vea en la vida de los hombres que no deban ser públicos, manteniendo estas cosas de manera que no se pueda hablar de ellas". ${ }^{11} \mathrm{El}$ juramento se ha ido reformulando en función de la cultura imperante y una versión actualizada fue dada por la Declaración de Ginebra en 1948. En esta, se menciona el respeto a los profesores y la hermandad que se crea entre médicos, pero, en la versión original, se incluye más información acer-

38 ca de la transferencia del conocimiento médico y las responsabilidades de esta fraternidad. ${ }^{12}$

11 En la versión actualizada, se hace referencia al término "secreto" en esta parte: "Respetaré el secreto de quien haya confiado en mí."

$12 \mathrm{El}$ texto del juramento hipocrático que hace referencia a profesores y aprendices dice: "A aquél que me enseñó este arte, le estimaré lo mismo que a mis padres; participará de mi mantenimiento y si lo desea partici- 
Es posible que el médico de Laura haya cultivado las artes médicas en un sistema de transmisión generacional y no que haya recibido una instrucción escolástica, por lo que sus conocimientos se muestran inexactos y es laxo en lo deontológico. Aun cuando el médico haya tenido una formación formal, el discernimiento de este sujeto en particular es escaso y su poder es anulado cuando la paciente se le escapa: "Pero cuando me hube convencido de que me hallaba libre de él, entrégueme a una loca alegría. Rompí el método del doctor, y comí, bebí, corrí, toqué el piano, canté y bailé: todo esto con el anhelo ardiente del cautivo que sale de una larga prisión. Parecíame que cada uno de estos ruidosos actos de la vida era una patente de salud; y olvidaba del todo la fiebre, la tos y los sudores, esos siniestros huéspedes de mi pobre cuerpo" (Gorriti 2006: 14). El lector se entera más del médico, porque la amiga a la que Laura le relata los hechos menciona que él es reconocido por sus méritos y esto crea una contradicción mayor, porque la caracterización del médico es negativa e, inclusive, se le describe monstruosamente: "él quien tiene sus manazas de largas uñas" (Gorriti 2006: 4).

Asimismo, es un médico distraído que no se da cuenta cuando ella bota el remedio, y del cual el lector puede burlarse en complicidad con Gorriti, al ser incapaz de reconocer a su paciente aun cuando la ha visto hace poco. Horas antes, en su conversación, Laura le había contado al médico

pará de mis bienes. Consideraré su descendencia como mis hermanos, enseñándoles este arte sin cobrarles nada, si ellos desean aprenderlo. Instruiré por precepto, por discurso y en todas las otras formas, a mis hijos, a los hijos del que a mí me enseñó, y a los discípulos unidos por juramento y estipulación, de acuerdo con la ley médica, y no a otras personas". 
que iba a transformarse en espíritu y que, en ese ensueño, él no la iba a poder reconocer ni con toda su ciencia, a lo que él respondió que sí podría por ser muy perspicaz. Poco más adelante en el relato, cuando se encuentran en la estación del tren, un muy distraído galeno no la reconoce y la piropea: "Adiós, cuerpecito de merengue. ¡Buen viaje, y que no te deshagas!" (2006: 9). Otro dato pertinente que Gorriti desliza al final de este capítulo es que el médico es español. Lo menciona para justificar que sepa tantos piropos y se introduce en el texto en tono de sorna.

Justificadamente, Laura opta por lo opuesto a lo recetado por su médico, pero, además, esto concede respuesta inmediata a sus pesares. Si bien la medicina se debería ocupar del bienestar físico, es a través del bienestar psicológico que se logra progreso en el estado de salud de la paciente. Se ha visto cómo ella empieza su proceso de sanación al proyectarse en la posibilidad del viaje y, ya para este momento, su mentada alegría no empieza con la mejoría del cuerpo, sino en el momento en el que ella se sabe libre de la tutela médica, que, en otros momentos, se menciona como tiránica.

\section{La tisis del alma ${ }^{13}$}

El doctor se refiere a la paciente como "tísica", pero existe una parte que desconoce o a la que se le niega el acceso:

13 La frase "tisis del alma" es utilizada por el personaje Adelina en Herencia, de Clorinda Matto de Turner: "Dicen que estoy tísica, ipero eso no es cierto!... Lo que me mata es otra tisis, sí, sí, la tisis del alma” (2006: 149). Este personaje secundario muere por un amor romántico y de tisis. 
el trasfondo psicológico de la enfermedad física. Incluso ella, Laura, sabe que hay un motivo que solo ella conoce: "Y yo me decía 'Como en mí, en él también, la dolencia del alma produjo la del cuerpo; y por ello más razonable que el doctor, que atacaba el mal sin cuidarse de la causa, recurrió al único remedio que podía triunfar de ambos: variedad de escenarios para la vida, variedad de aires para el pulmón"” (Gorriti 2006: 5).

Como bien lo retrata Susan Sontag, la tisis fue considerada como una peste que consumía a los enfermos, pero se permitió tener también una percepción artística que afectaba a las almas nobles o artísticas, e incluso les proveía de cierta vitalidad y los hacía seductores (1989:13). Así, la tisis se puede considerar una enfermedad que embellece a quien la padece y le otorga un lado puro y hermoso. Por defecto, la tisis consume a los héroes pasionales y es la enfermedad típica del Romanticismo. El amor no correspondido o prohibido provoca esta violencia corporal que culmina en la enfermedad y, de preferencia, la tisis romántica. Aunque el médico supiera el origen íntimo de la dolencia de Laura, tendría que tratarla por tuberculosis. Entonces, es substancial que su dolencia sea única, intrínseca del ámbito femenino, y que resulte opaca ante la medicina. En este caso, le mal du siècle tiene que ver con su esposo, que la ha abandonado por otra. Su problema sentimental surge del abandono marital y el cuerpo somatiza esta crisis como mejor puede, es decir, a través de una enfermedad romántica.

A lo largo de Peregrinaciones, los esposos están separados, pero, durante el viaje, él la contacta y pactan un posible reencuentro en la ciudad de Iquitos; sin embargo, cuando ella llega, se entera por un empleado de que él se ha ido a Europa 
con una supuesta esposa, es decir, con su amante; para evitar la deshonra y el escándalo, Laura resulta obligada a aparentar ser una prima de él. Luego de ser informada del viaje, la joven se desmaya y se siente desfallecer. Entre lágrimas, lee la carta que él le ha dejado y no solo acepta lo sucedido, sino que admite virtuosa su papel en ese matrimonio. La carta da señas del tipo de relación que tienen: “†Te amo, Laura mía! Tú eres mi solo, mi amor. ¿Es un ángel o un demonio el ser extraño que se ha colocado entre nosotros? [...] ¡Libértame de él, Laura mía! ¡Esta alma es tuya, sálvala! ¡Rompe el lazo infernal que encadena mi cuerpo, y vuélveme a tu amor!" (Gorriti 2006: 136). Cabe recalcar que es una relación muy moderna en la que el hombre admite abiertamente la relación extramarital y casi pide consejo a la esposa para seguir con la amante, pero también plagada del imaginario del ángel del hogar.

La mujer representa la parte espiritual del matrimonio mientras que el hombre se relaciona con la parte física. El sufrimiento y la enfermedad parecen ser parte de la simbología femenina y, en la dicotomía de cuerpo y alma, el cuerpo es una oportunidad para mejorar el alma. La joven no solo puede estar con él espiritualmente, sino que puede volver a poseerlo y salvar su alma: “'Me amaba! La más noble porción de su ser me pertenecía. Si otra mujer fascinaba sus sentidos, 42 su alma era mía” (2006: 137). Se entiende, entonces, que, a medida que su alma mejore, su cuerpo femenino responderá también al tratamiento anímico.

La justificación por parte de Laura del adulterio marital resulta insensata y un poco anacrónica para las reglas de decoro, pero, bajo los estándares de la época, no resulta inverosímil. Bajo los criterios de esa época, la mujer tenía una serie 
de deberes civiles, como la obligación de la buena crianza de los hijos, pero, incluso a finales de siglo, no se habían ampliado sus capacidades cívicas. ${ }^{14}$ Se debe entender que, en la historia republicana, las mujeres no tienen un espacio, pero sí una serie de obligaciones y deberes. A modo de conjetura, se comprende mejor la situación de la mujer en el texto, que no quiera separarse del marido y que prefiera plantear su traición como una prueba de espiritualidad. Es un caso anómalo, porque este estatus de mujer casada le confiere libertad y más posibilidades que si siguiera en la casa paterna, pero también la mantiene atada emocionalmente al marido y, por lo tanto, enferma. Además, como se vio, ella logra escapar de su casa sin mayor aspaviento familiar, aunque se trate de un escape, no de una salida.

En el caso de Laura, ella se conforma con tener el alma del amado, lo único que luego de su deceso los mantendrá unidos: "sabes que el dolor casi me llevó a la tumba" (Gorriti 2006: 114). El amor funciona como un pharmakon, porque es la cura y el veneno para la enfermedad de la mujer. La aporía es que ambas caras del amor funcionan como un par de opuestos que se anulan, ya que el amor espiritual, que es al que se aspira, es tan fuerte como idea que absorbe el amor físico y le quita todo su valor; es un equivalente al pareado de vida y muerte, en el que la muerte no es la ruptura de la vida, sino una continuación —además eterna — de esta. Así, aquello que se encuentra por encima de todo es la virtud.

14 La mujer no mantenía un estatus legal de ciudadanía: no podía vender sus bienes adquiridos por herencia ni atestiguar en un juicio ni cumplir con una función legal sin el consentimiento del marido (Aguilar 2006: 520). No es una cuestión de trato social, sino de mandatos constitucionales. 
Entonces, deja de importar el modo en el que vivan su vida marital y se enfoca la atención en cómo mantener la relación virtuosa, y al darle tanta importancia a ese momento futuro se desvirtúa totalmente el presente terrenal.

El amor romántico y el sentimiento de una instancia superior, divina, a la que se aspira, es constante. Al final del libro, Laura se entera de que su esposo ha luchado por restituir la nación de Hungría - él tiene nacionalidad húngara- y que ha sido apresado a perpetuidad en el castillo de Spielberg. Recibe una carta desde la prisión: “¿Lo creerás, amada mía? ¡Oh sí! ¡Créelo, yo te lo ruego! En esta miserable situación, soy feliz, porque puedo consagrar mi alma y mi vida a tu recuerdo. Aquí vivo contigo; y tu adorada imagen ilumina con una luz dulcísima las negras paredes de este encierro" (Gorriti 2006: 146). Ese período de reposo obligado sucede en una cárcel física, pero permite la libertad espiritual. En este momento, el esposo repite un discurso similar al de ella, excepto porque a él ya no le quedan otras alternativas. No puede hacer más respecto de su vida física, porque está aprisionado, así que tampoco podría serle infiel. Resulta irónico que él se proclame más feliz en este momento miserable porque puede dedicarse a amarla espiritualmente cuando, durante el tiempo de libertad, prefirió vivir aventuras con otra mujer. Inclusive al final del libro, se repite la imagen de este 44 amor espiritual que se nutre del amor físico hasta agotarlo, de este amor romántico que es una enfermedad que consume a los amantes.

En Peregrinaciones se encuentra otro caso similar. ${ }^{15}$ El de una

15 En la narrativa de Gorriti, es posible encontrar varios casos en los que la muerte permite la salvación de los personajes y en los que se siguen es- 
pareja - Carmela Villanueva y Enrique Ariel— que sufre porque ella ha ofrendado su vida a Dios cuando ya estaba enamorada de un hombre. Este episodio intercalado sirve de reflejo del amor y la situación de la protagonista. Esto ocurre de modo fortuito y siguiendo una fórmula de amor a primera vista admisible en el movimiento romántico. Ambos sufren constantemente, pero es el cumplimiento del deber, incluso más que el de la religión, lo que les obliga a mantener sus posiciones civiles y de clase. Después de una vida en tormento por no poder acceder al amado, la muerte resulta reparadora: el momento de tranquilidad llega a Carmela cuando él muere por salvaguardar el honor de ella, es decir, en un momento similar al del esposo de Laura en la prisión, cuando ya no existen más opciones en el mundo terrenal. ${ }^{16}$ Según la descripción de Laura, Carmela se ha convertido en un ser angélico: "El mundo me ha dado cuanto podía yo pedirle: las cenizas de mi esposo. Prosternada al lado de esas sagradas reliquias, espero tranquila la hora bendita en que mi alma vaya a unirse con la suya en la mansión del amor eterno" (2006: 74). Esta idea es consecuente con la devoción católica de Gorriti, aunque incongruente con su vida personal. Lo importante de la vida no es vivirla, sino concentrarse en lo venidero, que no es la muerte, según el pensamiento ca-

tándares del Romanticismo. Basta pensar en su famoso cuento La hija del mazorquero para analizar este motivo; pero, si bien es un tema frecuente, se presentan variantes en cada libro y este artículo se centra en la lectura de un solo texto y, en particular, de la protagonista.

16 Cabe recalcar que se hace énfasis en la similitud de este relato intercalado con la historia que articula todo el libro, pero ambas parejas muestran diferencias. Tal vez, lo más importante que se debe mencionar es que Carmela no tiene alternativas de vida, a diferencia de Laura quien, con sus diferentes viajes, logra abrirse espacios vitales. 
tólico, sino la vida eterna. Otra imagen del pharmakon en que vida y muerte se encuentran en un momento, y son caminos bifurcados que suceden a la vez.

\section{El viaje y el exilio}

La persona exiliada mantiene consigo los recuerdos de su sociedad y el trauma de la expulsión de su territorio. Puede, paralelamente, sentir el cambio sufrido y percibir la posibilidad que le anuncia el presente; la referencia a Las mil y una noches permite plantear las infinitas posibilidades que se desprenden de este desplazamiento en Peregrinaciones. El viaje del exilio le permite a aquel que sale del país sobrevivir y salvarse de la muerte, pero también lo envía a otro lugar a esperar esa muerte. No se trata del deceso físico, sino del martirio espiritual al ser sujeto en tránsito en tierras extranjeras. Aunque Juana Manuela Gorriti vivió buena parte de su vida en Bolivia y Perú por motivos políticos, siempre se encuentra en el texto su dolor por la tierra natal: “¡Oh! Hermosa patria, ¡Cuántos años de vida diera por contemplarte, aunque sólo fuera un momento, y como entonces te apareciste a mí, lejana, y velada por la noche, y cuántos daría esa alma desolada que ríe por no llorar!” (2006: 35). Nuevamente, se presenta la idea del pharmakon, al enfermarse uno al estar fuera de la patria y ser esta la que puede devolver la vida: "la patria es

46 un imán de atracción irresistible; y la savia de la tierra natal, el más poderoso agente de vida" (2006: 44). Es el acto de retorno o la presencia del terruño lo que se convierte en medicina para el enfermo. Es una sentencia funesta si su presencia en ese lugar está vedada y esa ambivalencia creará un pharmakon. Es el gozo incompleto de la restitución, ya que este acto rehabilita el estatus de la persona, pero esta queda para siempre escindida entre lugares y, por lo tanto, el retor- 
no no implicará el bienestar original y la utopía no fue —ni es- posible.

El pharmakos, que es un concepto que no se encuentra mencionado en el texto platónico, pero al cual se alude como explica Derrida (1981: 128-29), hace referencia al chivo expiatorio que es justamente el sujeto que se mantiene dentro de los bordes de la ciudad para poder castigarlo y eliminarlo de ser necesario a cuenta de que los dioses beneficien a la mayor parte de la población, y es un término que se evita en el texto, aunque su ausencia indica su presencia. Estos personajes suelen estar en lugares bilaterales, entre lo interno y lo externo, lo ausente y lo presente. Los exiliados se encuentran de algún modo en ese estado. Primero, se les permite vivir, pero fuera del territorio. Luego, están inhabilitados políticamente, pero permanecen a la espera del retorno o existen en un espacio externo a la nación. Al eliminarlos, se crea con ellos un rastro imposible de esconder y, de modo similar al pharmakos, su ausencia indica su presencia en el país de origen y en el de asilo. Mary Louise Pratt distingue narrativas de viaje —etnográfica y autoetnográfica-y, aunque el viaje de Laura no se encuadra en estos criterios, sí su escritora, que es el sujeto cuyo punto de vista diverge de aquel del centro de poder. Se podría afirmar que su lugar de enunciación, ese núcleo geopolítico de donde emerge su discurso, no es similar al que emite el discurso masculino y letrado de su época (Mignolo 2000: 12). Según Cristina Guiñazú, el texto de Gorriti no corresponde a ninguna de estas clasificaciones y es un registro novedoso en la narrativa de su época (2001: 79). Ciertamente, es un modo atractivo de llevar al lector a épocas y espacios variados, debido a las necesidades de movilidad de la protagonista. 
El caso de Gorriti fue complicado y escandaloso. Ella dejó la Argentina por una motivación política y familiar, pero no personal y, luego de su separación matrimonial en Bolivia, ${ }^{17}$ decidió partir, pero le estaba vedado regresar a su país de origen por las guerras civiles y porque las propiedades de los Gorriti en Salta habían sido adjudicadas a otros por el Gobierno. Entonces, fue al Perú, donde se estableció, escribió buena parte de su prolífica obra y adquirió fama como escritora. En su vejez, en 1882, regresó a Argentina porque se requería su presencia física para cobrar una pensión otorgada por el Gobierno, pero no vuelve a la provincia, sino a Buenos Aires, donde no había residido por mucho tiempo y que no siempre le sentaba bien:

He estado muy enferma, pero muy enferma, la mitad del mes pasado y lo que va de este. Decididamente el clima de Buenos Aires me es mortal y debo huir de él si quiero vivir. Siéntolo, porque, ahora como nunca, he encontrado en esta sociedad para mí dulces y calurosos afectos.

Además, esta es una ciudad espléndida, en la que se encuentra toda suerte de bienestar para el cuerpo y el espíritu.

Pienso, pasados estos dos meses de horroroso frío, hacer una gira por las provincias, para regresar al fin de la primavera, que en esas comarcas del interior es deliciosa. (Gorriti 1893: 174).

El texto anterior, que podría ser un comentario de Laura, fue escrito por la autora y revela las grandes similitudes con su personaje. Aunque Gorriti se integra a la vida intelectual, muestra en esta época añoranza por su círculo de amista-

17 El marido de Gorriti fue Manuel Isidoro Belzú (Bolivia, 1808-1865), presidente de Bolivia entre 1848 y 1855. 
des peruanas, como lo repite en sus cartas a Ricardo Palma: "Qué pena llevo conmigo de no volver a ver Lima, esa tierra para mí tan querida, donde habría querido dormir el eterno sueno al lado de mis hijos" (2004: 109). Gorriti dejó el norte argentino de adolescente y no vuelve al país hasta bastante adulta, así que lo que tiene en mente son sus recuerdos de infancia y ese es el referente de sus textos: una naturaleza paradisíaca y un entorno familiar feliz. Edward Said resume el procesamiento mental del exiliado: "For an exile, habits of life, expression, or activity in the new environment inevitably occur against the memory of these things in another environment. Thus both the new and the old environments are vivid, actual, occurring together contrapuntally" (2002: 186). ${ }^{18}$ Lo que se encuentra en su narrativa es la comparación entre estas dos realidades en constante oposición y la intención de hacerlas convivir con la mayor nitidez posible.

Debido a sus experiencias en el exilio, su mención al estadonación varía, pero eso no resta que esta mujer exiliada haya logrado representar a su nación en el extranjero. Resulta más importante recalcar que Gorriti fue una literata viajera que escribía desde un punto de enunciación móvil y movilizado a diferencia de otros escritores que no se ausentaron de su ciudad de origen. Este vacío dejado por el alejamiento del lugar de origen es representado en sus textos con constancia y esa nostalgia se vuelve el dolor perenne por la tierra natal. Es de lamentar y muy simbólico que solo retornó su cadáver

18 "Para un exiliado, los hábitos de vida, expresión o actividad en el nuevo ambiente ocurren inevitablemente contra los recuerdos de aquellos sucesos en otro ambiente. De este modo, ambos el ambiente nuevo y el antiguo son vívidos, reales y ocurren juntos contrapuntísticamente" (2002: 186). 
a su tierra. El ataúd de Gorriti fue trasladado de Buenos Aires a Salta, donde fue colocado en el Panteón de las Glorias del Norte en la Catedral de Salta. Es interesante que, para reformular el cuerpo político de la nación argentina, sea necesario regresar sus glorias, sus familias fundacionales, a la tierra natal.

A nivel textual, son innumerables los casos en los que se menciona el exilio y el viaje. Laura se bifurca imaginariamente en la joven que retorna a su patria y aquella que permanece inmóvil en su cama. Incluso luego de su partida, ella parece necesitar elegir entre dos polos: aquel de su realidad y aquel de la felicidad imaginada. La necesidad de movimiento de Laura es comparable a lo que sucede en el individuo exiliado que no se "mantiene" metafóricamente en un lugar fijo: "Exile is life led outside habitual order. It is nomadic, decentered, contrapuntal; but no sooner does one get accustomed to it than its unsettling force erupts anew" (Said 2002: 186). ${ }^{19}$ Esta inquietud es la motivación individual de ideas textuales que se extienden a varios personajes. En Peregrinaciones, se retrata la devastación que sufrió Paraguay tras la Guerra de la Triple Alianza. La cuñada de Laura es paraguaya y, aunque se alegra por su presencia, no puede dejar de pensar en lo sucedido: "Irene estaba triste durante estas dulces veladas; pero el motivo de su pena estaba lejos: era el triste estado 50 de su país, aniquilado por la guerra" (Gorriti 2006: 98). No siempre forzados por el exilio, sino por diversos motivos, algunos personajes huyen de sus casas. Entonces, no todos los viajes son motivados por el exilio y en la situación de Laura,

19 "El exilio es la vida fuera del orden habitual. Es nómada, descentrada y contrapuntística; pero tan pronto uno se acostumbra a ella, su fuerza inquietante vuelve a estallar" (Said 2002: 186). 
el motivo del viaje es su salud, ya que, ni bien se aposenta en un lugar, le regresa la tos. Para ella, el viaje es la cura, el pharmakon, aunque eso también la aleje de su tierra y de su familia, $y$, en ese sentido, la envenene.

Al alejarse de la casa paterna, Laura logra crear un espacio donde se rige por otras normas. El viaje es público y masculino, pero ella se apropia de él y, como propone Mary Berg, se libra de las expectativas sociales (1993: 77). Con esto, ella está creando un espacio heterotópico, que presenta la ilusión de la normatividad. En el caso de Laura, se crea una heterotopia de la crisis ${ }^{20}$ a partir del movimiento constante en el que se encuentra la mujer enferma y que deambula en espacios inusuales. Se evitan los marcadores geográficos para que la sanidad o enfermedad de la muchacha ocurra en "ningún sitio" y se debe enfatizar en lo ilocalizable. Este espacio por naturaleza está en relación con otros espacios; es decir, tiene nexos y recuerda a otros, pero, a la vez, los neutraliza al ser un espacio nuevo. Aunque se pueda localizar espacialmente, se refiere a un lugar diferente de la realidad, porque es un lugar creado artificialmente, es decir, en un discurso, para un propósito específico.

Respecto al viaje, Laura dice: "Es necesario; pues que sólo así puedo vivir" (Gorriti 2006: 75), es decir, en movimiento. Podemos encontrar más espacios heterotópicos en relación con mujeres en estado de crisis, tal como lo define Foucault,

20 Foucault explica en "De otros espacios. Heterotopias" que lo que él denomina las "heterotopias" de la crisis se refiere a lugares privilegiados o prohibidos donde se encuentran sujetos en crisis, debido a motivos personales y coloca a las mujeres embarazadas o menstruando como ejemplo. 
en la narrativa de estas escritoras y se organizan de modo diferente según el modelo social en el que se presentan. Es la crisis de la partida frente al acecho militar o de la huída frente a la devastación de la guerra, y, mientras dure este viaje, el tiempo se mantiene suspendido para evitar un lugar o un tiempo que otorgue especificidad.

Este concepto se vuelve relevante en la narrativa decimonónica, en la que el viaje y la reubicación espacial son dos temas imprescindibles para retratar la dislocación política que sufre la nación y los cambios socioeconómicos. Las posibilidades de desplazamiento de la mujer eran rígidamente reguladas por la normativa patriarcal; sin embargo, hechos externos como las guerras territoriales, las disputas provinciales y las rivalidades caudillistas relativizan el modelo. Las escritoras a través de la economía narrativa de sus relatos naturalizan acciones subversivas dentro de un discurso relacionado con desplazamiento y fronteras. Todo esto nos ayuda a entender la transformación que están sufriendo el espacio privado y el público, y la intrusión de uno en el otro en la segunda mitad del siglo XIX.

En este siglo, el viaje puede ser bastante turbulento, pero permite el acceso a otras regiones tal como sucede en el libro. Laura viaja en balsa, en hombros, en tren y a caballo;

52 luego, se trasviste, aprende un lenguaje más "florido" y costumbres nuevas, y conoce a personajes que llenan su cabeza de historias. La imagen de la mujer liberada, viajera, imaginada por Gorriti es una versión literaria de ella misma. Es casi imposible pensar en una Laura existente $y$, en ese sentido, los referentes son estas escritoras independientes que están jugando siempre en los márgenes de lo hegemónico y que terminan finalmente expulsadas. El nombre de su libro evo- 
ca el de otra viajera, la franco-peruana Flora Tristán (Francia, 1803-1844), cuyo libro, Peregrinaciones de una paria, fuera quemado en el Perú por inmoral en 1832. Si el personaje de Laura resulta sorprendente es porque solo podría existir en la imaginación de una mujer como Gorriti, acostumbrada a negociaciones culturales con el entorno - concreto y textual-. Entre las publicaciones de Gorriti, se halla también La tierra natal (1888), que "altera las modalidades literarias en boga. En un época en que el relato de viaje es vehículo de ideas importadas de los centros de civilización, Gorriti lo aplica a un lugar remoto del interior de América" (Guiñazú 2001: 103). Con este libro, retoma su punto de vista de la provincia argentina que mantiene en sus recuerdos, a diferencia del ser bonaerense.

Como se observa, temas comunes en la narrativa de Juana Manuela Gorriti son el escapismo a través de la lectura o la narración del viaje. Ward propone que las mujeres buscaron medios alternos para contrarrestar la realidad que existía: "Fueron las mujeres a quienes les estaban cerradas las puertas laborales y el acceso a la tecnología quienes ocuparon un espacio atecnológico, más natural para acudir al pasado con el fin de reparar un presente defectuoso" (2006: 3). La autora escribe su mejor y más prolífica obra exiliada, y, para ella, la escritura es un modo de retorno a la tierra natal o a un espacio idílico en el continente americano. Aunque no es sujeto político en su país, se permite tener agencia al tener voz desde el exilio y revivir la nación que rememora, que posiblemente hace referencia a la patria chica. Para utilizar el mismo término, se puede afirmar que su pharmakon es la escritura y, así, ella vive para escribir y vive porque escribe. 


\section{Conclusiones}

Como se ha comprobado en este ensayo, al asumir un punto de vista diferente, es posible reivindicar a grupos minoritarios. Aunque Gorriti no haya tenido la intención de desarticular la epistemología del conocimiento, sí desafía la rigidez de esta al colocar al mismo nivel un tipo de conocimiento que se considera menor -el perteneciente al espacio doméstico o familiar- y el aceptado socialmente como conocimiento formal. Así, se contrapone la ciencia médica con la lógica femenina, la memoria local con la historia oficial, ${ }^{21} \mathrm{y}$ así esta escritora excede los márgenes de lo normativo. En general, Gorriti otorga importancia a otra fuente de conocimiento - femenino_- que propone como alternativa frente al conocimiento tradicional o académico, favorecido este último por las prácticas de la colonialidad extendidas en toda América Latina.

La medicina preserva el sistema paternalista de la nación en los cuerpos femeninos. Laura escapa de la casa y crea una ruptura con este orden, pero lo hace por la enfermedad romántica del amor y sobrevive a la tuberculosis por él. El uso de fármacos inútiles no implica un ataque completo contra el positivismo, sino, más bien, un ataque parcial contra las instituciones masculinas que atan a la mujer y contra el conocimiento institucionalizado que socavaba las necesidades femeninas. El viaje del exilio muestra las particularidades de la escritora y también demuestran cómo sus motivaciones

21 Varios trabajos críticos proponen que incluso un inocente discurso culinario cumple con esta función desestabilizadora del conocimiento tradicional y de las normas patriarcales. Es un tema que se presenta con varios carices en otros textos. 
tienen eco en la narrativa. La necesidad de movimiento constante y el lugar inubicable crean espacios heterotópicos que apuntan al problema de la dislocación espacial. El relato de viaje presenta la transformación de los espacios y, a partir de acciones textuales subversivas, se contradice el agenciamiento tradicional dado a los hombres en la estado-nación.

Resulta fundamental seguir haciendo lecturas críticas de la narrativa de Gorriti, una escritora a quien, a veces, se le considera menor, pero cuyos textos esconden multiplicidad de significados y la rebeldía de un alma que no se conforma con las injusticias sociales y la opresión de su género.

Recibido: 15 de mayo del 2017

Aprobado: 16 de agosto del 2017

\section{Bibliografía}

AGUILAR GIL, Roisida

2006 "La 'aurora' del sufragio femenino en el Perú: Zoila A. Cáceres, 1924-1933”. En O’PHELAN GODOY, Scarlett y Margarita ZEGARRA FLÓREZ. Mujeres, familia y sociedad en la historia de América Latina, siglos XVIII-XXI. Lima: Centro de Documentación sobre la Mujer, Instituto Riva Aguero, Instituto Francés de Estudios Andinos.

Asamblea General de la Asociación Médica Mundial

1984 Juramento hipocrático. Consulta: 25 de noviembre de 2016. <http://www.bioetica.org/cuadernos/contenidos/hipocrates.htm>

BATTICUORE, Graciela

2004 Juana Manuela Gorriti. Cincuenta y tres cartas inéditas a Ricardo Palma. Lima: Universidad San Martín de Porres. 
BERG, Mary 1993

"Viajeras y exiliadas en la narrativa de Juana Manuela Gorriti". En FLETCHER, Lea. Mujeres y cultura en la Argentina del siglo XIX. Buenos Aires: Feminaria, pp. 69-79.

BOURDIEU, Pierre

1993 The Field of Cultural Production. Essays on Art and Literature. Nueva York: Columbia University Press.

BORGES, Jorge Luis

2006 Ficciones. Buenos Aires: Emecé.

DERRIDA, Jacques

1981 Dissemination. Chicago: University of Chicago Press.

FOUCAULT, Michel

1987-2000 Of other Spaces. Heterotopias. Traducción de Jay Mis[1967] kowiec. Consulta: 02 de octubre del 2017<www.foucault.info>

GORRITI, Juana Manuela

1893 Lo intimo. Buenos Aires: Ramón Espasa.

1889 La tierra natal. Buenos Aires: Santiago Estrada.

2006 [1876] Peregrinaciones de una alma triste. Buenos Aires: Stockcero.

GUIÑAZÚ, Maria Cristina y Claire MARTIN

2001 Las mujeres toman la palabra. Escritura femenina del siglo XIX en Hispanoamérica. Volumen 1. Madrid: Iberoamericana.

MANNARELLI, María Emma

1999 Limpias y modernas. Género, bigiene y cultura en la Lima del novecientos. Lima: Flora Tristán. 
MASIELLO, Francine

2003 "Women as Double Agents in History". En CASTRO KLARÉN, Sara. Latin American Women's Narrative: Practices and Theoretical Perspectives. Frankfurt: Vervuert.

1992 Between Civilization and Barbarism. Women, Nation, and Literary Culture in Modern Argentina. Lincoln: University of Nebraska Press.

MATTO DE TURNER, Clorinda

2006 Herencia. Buenos Aires: Stockcero.

MIGNOLO, Walter

2000 Local Histories/Global Designs: Coloniality, Subaltern Knowledges and Border Thinking. New Jersey: Princeton University Press.

PRATT, Mary Louise

1992 Imperial Eyes, Travel Writing and Aculturation. New York: Routledge.

PRICE, Diane

Invalid Women. Figuring Feminine Illness in American fiction and Culture 1840-1940. Chapel Hill y Londres: University of North Carolina Press.

RODRÍGUEZ, Ileana

1994 House, Garden, Nation. Durham y Londres: Duke University Press.

SAID, Edward

2002 Reflexions on Exile and Other Essays. Cambridge: Harvard University Press.

SHOWALTER, Elaine

1985 The Female Malady. Women, Madness, and English Culture, 1830 - 1980. New York: Penguin. 
SILVA BEAUREGARD, Paulette

2000 De médicos, idilios y otras historias: relatos sentimentales y diagnósticos de fin de siglo. Bogotá: Convenio Andrés Bello.

SONTAG, Susan

$1989 \quad$ Illness as Metaphor and AIDS and Its Metaphors. New York: Picador, Farrar,

Straus and Giroux.

URRACA, Beatriz

1999 "Juana Manuela Gorriti and the Persistence of Memory". Latin American Research Review. Alburquerque, volumen 1, número 34, pp. 151-73.

WARD, Thomas

2006

"Ficción histórica peruana: las escritoras comprometida". En GUARDIA, Sara Beatriz. Mujeres que escriben en América Latina. Lima: Centro de Estudios de la Mujer en la Historia de América Latina. 